\title{
A EXTENSÃO UNIVERSITÁRIA COMO POSSIBILIDADE DE FORMAÇÃO INTEGRAL: EVOLUÇÃO, SUJEITOS ENVOLVIDOS, APRENDIZAGEM E INSERÇÃO CURRICULAR
}

DOI: dx.doi.org/10.18616/inser02

Merlin Janina Diemer ${ }^{1}$

\section{INTRODUÇÃO}

A história da extensão nas universidades brasileiras transcorre por diferentes modelos e por muitos anos. Ela esteve desvinculada das atividades acadêmicas de ensino e pesquisa. Isso ocorreu, em parte, pela extensão ter existido como respostas imediatas às necessidades da sociedade e pela característica que assumiu de difusão dos conhecimentos produzidos pela universidade. Nos últimos anos, esse quadro vem se modificando no cenário brasileiro e, a partir de 1980, a extensão começou a aparecer nos documentos oficiais do governo, ocupando o mesmo patamar que o ensino e a pesquisa.

Este capítulo perpassa por essa história, a fim de construir uma reflexão a partir do novo modelo que começa a ser propagado com a criação dos Fóruns de Pró-Reitores de Extensão das Instituições Públicas de 1987 e com a Constituição Federal de 1988. Em 2004, o Sistema Nacional de Avaliação da Educação Superior (SINAES) incluiu a extensão nos indicadores de avaliação das IES, requerendo a participação dos estudantes nas ações extensionistas e aferindo o impacto na sua formação. Por fim, no ano de 2014, em consonância com o esforço nacional para que a extensão fosse parte integrante do fazer acadêmico, o novo Plano Nacional de Educação

${ }^{1}$ Mestre em Arquitetura. É professora do curso de Arquitetura e Urbanismo da Universidade do Vale do Taquari - UNIVATES.E-mail: merlin@univates.br 
Superior (2014-2024) apresentou como meta para todas as IES garantir $10 \%$ da carga horária em programas e projetos de extensão universitária.

Dessa forma, este capítulo apresenta as diferentes concepções que nortearam a temática de extensão na história brasileira, bem como faz uma breve análise crítica do modelo de extensão pactuado a partir do Fórum das IES públicas de 1987, que a conceituou como uma via de mão dupla entre universidade e comunidade, refletindo sobre o impacto desse modelo, a definição dos sujeitos envolvidos, o conceito de programas e projetos e uma possibilidade de inserção curricular.

Também procura mostrar que a extensão não deve ser vista somente como ação que possibilita a interação entre universidade e sociedade a fim de que cumpra o seu papel e dever de estar comprometida com a construção da sociedade onde está inserida. A extensão é uma possibilidade de aprendizagem para o estudante, que, ao estar envolvido com as ações extensionistas, é beneficiado por conhecimentos que contribuem para o seu desenvolvimento pessoal e profissional, visando a uma transformação qualitativa dele como ser humano e cidadão, com consciência crítica e preparado para enfrentar as realidades diversas.

\section{OS ATOS LEGAIS E OS MODELOS DE EXTENSÃO DESVINCULADOS DO ENSINO E DA PESQUISA}

O percurso histórico da universidade brasileira mostra que a extensão transitou por diferentes modelos até que, na década de 80 , a necessidade de indissociabilidade da tríade ensino, pesquisa e extensão foi incluída na Constituição Federal Brasileira de 1988, apresentando, pela primeira vez, a extensão como uma atividade acadêmica no mesmo nível do ensino e da pesquisa. 
O conceito de extensão não surge concomitantemente com o de ensino. Prioritariamente, a preocupação das universidades foi especificar a função "ensino", passando a incorporar, gradativamente, a função "pesquisa" como característica do ambiente acadêmico. Os primeiros relatos de concepções da função "extensão" no Brasil são datados entre os anos de 1911 e 1917, na Universidade Livre de São Paulo. A proposta inicial da extensão universitária foi a promoção de conferências, cursos e semanas abertas de estudos. Esse modelo foi realizado pelas elites e para as elites, dissociado do ensino, da pesquisa e de questões políticas (SÍVERES et al., 2009).

A promulgação do Estatuto da Universidade Brasileira, em 1931,2 marca a existência da extensão em atos legais, formalizando um modelo de extensão universitária. Essa compreensão foi apresentada como sendo a realização de atividades de difusão de conhecimentos a fim de elevar o nível daqueles que não estão vinculados diretamente à universidade. A extensão aparece como função da universidade, oferecida por meio de "[...] cursos de extensão universitária destinados a prolongar, em benefício coletivo, a atividade técnica e científica [...]" desenvolvida nos espaços acadêmicos (SÍVERES et al., 2009, p. 13-14; DUCH, 2006, p. 24).

O Estatuto legislava a extensão como sendo designada a "[...] dilatar os benefícios da atmosfera universitária àqueles que não se encontram diretamente associados à vida da universidade." (SÍVERES et al., 2009 , p. 14). A ideia era elevar o nível cultural do povo e solucionar problemas sociais. Nessa época, embora a extensão se caracterizasse como um prolongamento da ação acadêmica, destinada à difusão de conhecimentos, ainda não se relacionava com o ensino e com a pesquisa. Nesse sentido, a prática se distanciou do texto legal, cujos cursos ministrados nas faculdades complementavam a formação dos seus próprios acadêmicos ou egressos, excluindo as camadas populares de poder econômico reduzido (NOGUEIRA, 2001).

${ }^{2}$ Decreto no 19.851, de 11 de abril de 1931 (BRASIL, 1931). 
Nas duas décadas subsequentes, não há qualquer outra menção da função da extensão nos atos legais anunciados pelo Ministério da Educação. A temática é retomada em textos legais somente em 1961, com a Lei de Diretrizes e Bases da Educação Nacional ${ }^{3}$, a qual apresenta, em seu artigo 69 (BRASIL, 1961), rápida referência à extensão como um conjunto de atividades que as universidades poderiam executar na forma de cursos, aperfeiçoamentos e especializações. Dessa forma, corrobora-se o fato da extensão dirigir-se à comunidade que já frequentava a universidade.

Nos Estatutos do Magistério Superior, de 1965 e $1968^{4}$, o papel da extensão era caracterizado como dispensável e complementar. As funções de ensino e de pesquisa, por sua vez, nesse documento, são características da vida acadêmica e das atividades docentes, sem mencionar a extensão como uma função da universidade ou inerente às atividades acadêmicas (DUCH, 2006). Projetos como o Centro Rural de Treinamento e Ação Comunitária (CRUTAC) e o Projeto Rondon, criados em 1966, foram considerados iniciativas importantes para a história da extensão, propiciando ao universitário importantes experiências nas comunidades rurais, contribuindo para a melhoria das condições de vida da população.

Outro modelo de extensão foi dado a partir da Reforma Universitária de 1968, momento em que a extensão universitária passou a ser entendida sob uma perspectiva assistencialista. As atividades de extensão, nesse momento, ocorreram por meio da prestação de serviços às populações menos favorecidas, mediante a assistência social para as comunidades carentes, desvinculadas do ensino e da pesquisa (SÍVERES et al., 2009; FORPROEX, 2006). Assim, as ações extensionistas se tornaram obrigatórias; entretanto, elas assumiram uma função social a serviço do Estado.

${ }^{3}$ Lei n ${ }^{\circ}$ 4.024, de 20 de dezembro de 1961, fixa as Diretrizes e Bases da Educação Nacional. Art. 69 - Nos estabelecimentos de ensino superior, podem ser ministrados os seguintes cursos: [...] c) de especialização, aperfeiçoamento e extensão, ou quaisquer outros, a juízo do respectivo instituto de ensino, abertos a candidatos com o preparo e os requisitos que vierem a ser exigidos. (BRASIL, 1961, n.p.).

${ }^{4}$ Lei $\mathrm{n}^{\circ} 4.881$ e Lei $\mathrm{n}^{\circ} 5.539$, respectivamente. 
Observa-se que a Lei no 5.540, promulgada em 1968, contempla a comunidade e os discentes, excluindo da concepção de extensão a participação dos docentes.

Art 20 -[...] as universidades e as instituições de ensino superior estenderão à comunidade, sob forma de cursos e serviços especiais, as atividades de ensino e os resultados da pesquisa que lhe são inerentes [...]

Art. $40-[\ldots]$

a) as instituições de ensino superior, por meio de suas atividades de extensão, proporcionarão aos seus corpos discentes oportunidades de participação em programas de melhoria das condições de vida da comunidade e no processo geral de desenvolvimento. (BRASIL, 1968b, n.p. Grifos meus).

Cabe destacar que a comunidade sempre aparece como uma receptora de informações ou de atendimento prestado pela universidade, mas, em nenhum momento, ela é mencionada como um sujeito articulador para a troca de saberes. Os textos legais demonstram, até o momento, uma extensão desarticulada das atividades acadêmicas do ensino e da pesquisa, apesar de dependente delas. São cursos, aperfeiçoamentos, promoção de eventos ou prestação de serviços que são estendidos à comunidade como resultados do ensino e da pesquisa, mas não articulados a eles.

Todavia, paralelo a essa questão legal, foi desenvolvido outro modelo de extensão, praticado na década de 60. Nele, estudantes realizavam atividades extensionistas, as quais rompiam os muros da universidade, indo ao encontro das comunidades, que foram denominadas "desenvolvimento da comunidade". O modelo propunha o diálogo dos saberes, que se caracterizava pela troca de experiências entre estudantes e membros de uma comunidade carente. $\mathrm{O}$ estudante participava da vida social das co- 
munidades, ensinando e aprendendo com e na comunidade. Conforme Nogueira (2001), a maior contribuição desse modelo foi a metodologia de trabalho que possibilitava a reflexão sobre as ações realizadas, porém não impactou a universidade como um todo, e o governo militar, na reforma de 68, tratou-a como assistencialismo (SÍVERES et al., 2009; NOGUEIRA, 2001).

Mesmo o retrocesso imposto à Extensão Universitária pelo governo militar, dando-lhe uma feição assistencialista, não impede que essas ideias, delineadas pelos estudantes, reapareçam, superem-se e se consolidem em nova concepção presente na fase posterior. (NOGUEIRA, 2001, p. 62).

Na década de 70, ocorreu uma compreensão de extensão instituída pelas indústrias, devido à necessidade de mão de obra qualificada para diversos trabalhos. As indústrias sentiram a necessidade de formar técnicos qualificados para diversas áreas, e a Universidade, sendo procurada pela indústria, não soube localizar essa demanda e a identificou como atividades de extensão, devido ao desenvolvimento de cursos especializados, consultorias e assessorias a grandes empresas (SÍVERES et al., 2009).

Ainda na década de 70, foram traçadas Diretrizes de Extensão pelo CRUB (Conselho de Reitores das Universidades Brasileiras), o qual passou a defender que a Universidade se firmava nas três funções - ensino, pesquisa e extensão -, considerando a extensão um “[...] desdobramento natural da atividade didática.” (NOGUEIRA, 2001, p. 64).

Em 1975, o MEC (Ministério da Educação e Cultura) constituiu a primeira política de Extensão Universitária, chamada Plano de Trabalho de Extensão Universitária. Segundo Nogueira (2001), o plano superou a proposta pela reforma universitária de 1968, pois também procurou envolver docentes. Apesar de Sousa (2000) comentar que o plano não traduzia 
nenhum avanço em relação à concepção de extensão, cabe destacar que o texto restaurou o envolvimento unilateral da extensão, ou seja, da universidade para a comunidade. A interpretação do texto sugere a troca entre saber acadêmico e saber popular ao descrever que o papel da extensão é atender à comunidade, às organizações, a outras instituições e a população e, delas, receber "[...] influxo no sentido de retroalimentação dos demais componentes, ou seja, o ensino e a pesquisa." (NOGUEIRA, 2001, p. 66). Associada à redefinição das práticas de ensino, pesquisa e extensão, também foi questionada a visão assistencialista das ações extensionistas.

\section{A EXTENSÃO FIRMADA A PARTIR DA DÉCADA DE 80: PROGRAMAS, PROJETOS E INSERÇÃO CURRICULAR}

Na década de 80, a partir da aliança entre setores da política e de várias universidades, um novo conceito de extensão universitária começou a ser disseminado. As atividades de extensão, em conjunto com as de ensino e pesquisa, passaram a ser consideradas, oficialmente, como atribuições do corpo docente. Na passagem dos anos 80 para os 90, a temática da extensão esteve presente nas agendas de discussão dos Fóruns de Pró-Reitores de Extensão das IES. Em 1987, foi criado o Fórum Nacional de Pró-Reitores das Universidades Públicas Brasileiras. Em 1999, foi a vez do Fórum Nacional de Extensão e Ação Comunitária das Universidades e Instituições de Ensino Superior Comunitárias. Em 2003, foi criado o Fórum de Extensão das IES particulares. A partir do primeiro fórum das IES públicas, ficou expressa a necessidade de uma intervenção da Universidade na sociedade onde se insere, tendo o fórum definido que a extensão "[...] viabiliza a relação transformadora entre universidade e sociedade." (FORPROEX, 2001, p. 29).

Nesse mesmo fórum, houve um avanço na conceituação da extensão universitária, sendo incluída no plano institucional e na proposta peda- 
gógica das universidades como uma ação comprometida com a realidade social (FORPROEX, 1987).

A Constituição Federal de 1988, como já apresentada no início da seção anterior, caracterizou, pela primeira vez, em textos legais, a extensão como uma função da universidade ao determinar em seu artigo 207 que “[...] as universidades gozam de autonomia didático-científica, administrativa e de gestão financeira e patrimonial, e obedecerão ao princípio de indissociabilidade entre ensino, pesquisa e extensão." (BRASIL, 1988, n.p.).

Anos mais tarde, a Lei $\mathrm{n}^{\circ} 9.394 / 1996$, ao estabelecer as bases da educação nacional, fez menções à extensão, sem, contudo, defini-la. Em seu capítulo IV, a LDBE atribui à Educação Superior a promoção da extensão.

Art. 43. A educação superior tem por finalidade:

$[\ldots]$

VI - Estimular o conhecimento dos problemas do mundo presente, em particular os nacionais e regionais, prestar serviços especializados à comunidade e estabelecer com esta uma relação de reciprocidade;

VII - Promover a extensão, aberta à participação da população, visando à difusão das conquistas e benefícios resultantes da criação cultural e da pesquisa científica e tecnológica geradas na instituição. (BRASIL, 1996, n.p. Grifos meus).

Foi também a partir desse momento que se instituiu o sistema de Diretrizes Curriculares e, com ele, ocorreu a inclusão das atividades denominadas complementares, inserindo-as como parte do processo de formação dos estudantes de graduação.

Não obstante, a partir de 2004, a importância da extensão universitária enquanto atividade acadêmica também foi reconhecida pelo Sistema 
Nacional de Avaliação da Educação Superior (SINAES), que a incluiu na avaliação das IES. O SINAES estabeleceu as ações da extensão como indicadores de avaliação, dentre os quais aparece a concepção de extensão e interação social afirmada no Plano de Desenvolvimento Institucional (PDI), a articulação das atividades de extensão com o ensino e a pesquisa e com as necessidades e demandas do entorno social, e a participação dos estudantes nas ações de extensão e intervenção social e o respectivo impacto em sua formação (BRASIL, 2004).

Enfim, observa-se que há um esforço nacional para que a extensão universitária seja reconhecida como parte integrante do fazer acadêmico, ao lado do ensino e da pesquisa, inserida nos projetos pedagógicos dos cursos e formalizada institucionalmente. Em consonância com o exposto acima, o novo Plano Nacional de Educação (PNE - 2014-2024) ${ }^{5}$ formaliza como meta às IES a inserção da extensão como parte dos créditos curriculares. A meta 12.7 apresenta que os currículos de graduação devem assegurar, no mínimo, $10 \%$ do total de créditos exigidos para a graduação em programas e projetos de extensão universitária.

O Plano Nacional de Educação Universitária anterior, de 20012010, já mencionava a necessidade de os acadêmicos cumprirem créditos em extensão universitária, porém há diferenças do PNE 2001-2010 para o PNE 2014-2024. A primeira delas diz respeito à abrangência das instituições. Enquanto o plano 2001-2010 apresenta a necessidade para as instituições públicas, o plano 2014-2024 amplia para todas as instituições de ensino superior brasileiras. Outra alteração se refere à caracterização e à abrangência da extensão. No PNE 2001-2010, há referência de que as instituições devem assegurar 10\% dos créditos em ações extensionistas, enquanto o PNE 2014-2024 estabelece que os 10\% dos créditos sejam em programas e projetos de extensão.

Ao dar prosseguimento a essa compreensão, a discussão conceitual e a prática de extensão pareciam estar sendo coordenadas pelos Fóruns

${ }^{5}$ Lei no 13.005 , de 25 de junho de 2014. 
das Instituições, uma vez que os textos legais não formalizavam conceituações. O Fórum das Instituições Públicas pactuou as seguintes definições para o programa e os projetos de extensão.

Programa - conjunto articulado de projetos e outras ações de extensão (cursos, eventos, prestação de serviços), preferencialmente integrando as ações de extensão, pesquisa e ensino. Tem caráter orgânico-institucional, clareza de diretrizes e orientação para um objetivo comum, sendo executado a médio e longo prazo;

Projeto - ação processual e contínua de caráter educativo, social, cultural, científico ou tecnológico, com objetivo específico e prazo determinado. $O$ projeto pode ser vinculado a um programa [...] e não vinculado a programa. (FORPROEX, 2007, p. 35. Grifos meus).

O Forproex também definiu que as ações de extensão podem ser classificadas em programa, projeto, curso, evento e prestação de serviços, que se desdobram em aperfeiçoamento, cursos de curta, média e longa duração, educação continuada ou eventos com duração de menos de oito horas (FORPROEX, 2007).

Aliada a esses conceitos, é possível sugerir uma interpretação para o item referido à extensão nos últimos dois PNEs. O PNE 2001-2010 permite interpretar que os $10 \%$ incorporam qualquer ação de extensão. Dessa forma, seria possível englobar no computo dos $10 \%$ qualquer curso, palestra, aperfeiçoamento e prestação de serviço oferecidos de forma isolada e desvinculados de programas. Já o PNE 2014-2024 estabelece que os $10 \%$ dos créditos devem ser assegurados por programas e projetos, sendo que ações caracterizadas como cursos, eventos ou prestação de serviços 
serão consideradas se estiverem articuladas a um programa ou projeto de extensão.

Cabe compreender como operacionalizar esse percentual em currículos da graduação. Sobre esse assunto é importante uma reflexão: em 1988, a Constituição Federal instituiu que as universidades obedeceriam ao princípio de indissociabilidade entre ensino, pesquisa e extensão. Compreende-se que o currículo da graduação deveria ser $100 \%$ indissociável, por meio do qual o mesmo estudante, na mesma atividade, estaria fazendo ensino, pesquisa e extensão. O ensino refere-se ao princípio da aprendizagem. Para ele ser efetivo, o estudante realiza a investigação, que se refere ao princípio da pesquisa. A construção do conhecimento ocorre por meio das tensões e trocas de saberes entre academia e comunidade, objetivando a reconstrução do conhecimento. Esse enfrentamento do cotidiano que inspira o diálogo entre universidade e comunidade faz alusão ao princípio da extensão como um dos elementos fundamentais da indissociabilidade. Aprender é, nesse sentido, um processo intrinsecamente ligado à vida e implica a possibilidade de reconstrução do conhecimento pelo estudante, que passa pela autonomia do aluno.

Entretanto, a reflexão acima não ocorre na maioria das práticas. Ao ter em vista que a primeira atividade da universidade foi o ensino, depois a pesquisa e, posteriormente, foi incorporada a extensão, nossa cultura universitária e os currículos estão "fatiados" e a indissociabilidade requer outros exercícios, como, por exemplo, o de revisão metodológica e de compreensão de como um estudante apreende. Já está comprovado, por meio de pesquisas, que não retemos tudo o que ouvimos, escutamos ou lemos, e que o método mais eficaz é a prática. Retemos muito mais quando praticamos, do que somente lendo, ouvindo ou escutando. O psicólogo Edgar Gale publicou, em 1946, um estudo a esse respeito, comentando que, após duas semanas, retemos apenas $10 \%$ do que foi lido, $20 \%$ do que foi ouvido e $30 \%$ do que foi visto. Em contrapartida, é possível lembrar que retemos $90 \%$ quando simulamos uma experiência real, participamos ou realizamos 
uma prática (FRANCO; SILVEIRA; BRAGA, 2004). Todavia, o modelo de sala de aula tradicional ainda persiste nas nossas universidades e a indissociabilidade entre ensino, pesquisa e extensão sugere uma nova postura epistemológica. A postura epistemológica disciplinar não dá conta de resolver os problemas contemporâneos e, portanto, há necessidade de superarmos as fronteiras disciplinares. Em suma, diferentes questões apontam para a necessidade de uma nova sala de aula que possa oferecer práticas comprometidas com a aprendizagem do estudante e a extensão. Nessa perspectiva, a sala de aula é um espaço estratégico para construir experiências de formação e de aprendizagens de natureza interdisciplinar.

Os elementos acima mencionados acendem para um currículo interdisciplinar e indissociável, mas é um ideal ainda a ser alcançado ante os nossos currículos disciplinares, lineares, de grade fechada e que dão uma visão rígida da formação, somados à organização institucional burocrática que dificulta a interação com a realidade e a dinâmica do mundo social. Além disso, muitas vezes, na sala de aula, estão os professores conteudistas que contribuem para a visão "fatiada" dos componentes curriculares. Cabe, então, a introdução gradativa de novas práticas pedagógicas que articulem o ensino, a pesquisa e a extensão na construção de uma "nova sala de aula". Por meio de um mapeamento de todas as disciplinas ofertadas pelos cursos da instituição, é possível verificar as disciplinas potenciais para fomentar a indissociabilidade e, gradativamente, esse modelo pode ser disseminado para as demais disciplinas. Paralelo a isso, é importante estudar outras alternativas para que a extensão seja introduzida nos currículos, uma vez que ainda estamos a passos lentos de fazer com que todos os docentes saibam como lidar com essa nova sala de aula e estejam capacitados para essa prática pedagógica. Uma alternativa que está sendo estudada ${ }^{6}$ é a instituição constituir projetos de extensão que desenvolvam habilidades para os diferentes estágios do curso. Projetos que contribuam para o desenvolvimento de habilidades iniciais de um curso de graduação, para o desenvolvimento de habilidades relacionadas à metade de um curso de graduação e para o

${ }^{6}$ Estudo em curso na Universidade do Vale do Taquari, em Lajeado - RS. 
desenvolvimento de habilidades finais de uma graduação. Essas diferentes habilidades levam à aquisição de competências, que podem ser de diferentes naturezas, sejam de formação humana, profissional ou empreendedora, por exemplo. Assim, em diferentes momentos do curso, o aluno poderia optar por projetos que contribuam para o desenvolvimento dessas competências. Essa alternativa é interessante, pois possibilita a flexibilização e a ideia de liberdade, fomentando a autonomia do estudante para que ele possa construir o seu caminho, o seu currículo e a sua identidade. Isso não significa inchar ou acrescentar disciplinas optativas no currículo, pelo contrário, significa trabalhar parte dos créditos de disciplinas já existentes em formato de extensão (articulando ensino e pesquisa). Além disso, o projeto não seria fixo, de uma disciplina. Nesse caso, o estudante poderia optar por um leque de possibilidades de projetos para cursar no início, na metade e no final do curso, as quais perpassam pelas competências a serem desenvolvidas nos diferentes estágios.

Em qualquer um dos casos, o requisito fundamental para a extensão universitária é envolver o estudante como protagonista principal e que a extensão seja proposta no sentido de contribuir para a formação dele. Tem-se detectado, em algumas situações acadêmicas, que a postura dos alunos nos últimos anos perpassa a falta de interesse, de motivação, de comprometimento com a própria aprendizagem, de individualismo, de interesse somente pela nota e de falta de criticidade. Nesses casos, é importante verificar o quanto a instituição está contribuindo para tal postura. A extensão é um caminho para que o trajeto educativo do aluno passe por uma ação exploratória além dos conteúdos das disciplinas de sala de aula. A flexibilização curricular permite ao acadêmico escolher o projeto, alterando o percurso universitário de aluno para aluno, afinando-o, assim, com o seu interesse de formação. A extensão proporciona ao estudante uma experiência universitária que marca a sua vida acadêmica. Nesse sentido, a escolha do projeto favorece o desenvolvimento afetivo do aluno, dando espaço para que tais experiências influenciem positivamente a sua formação. 


\section{CONCEITUAÇÃO, SUJEITOS E APRENDIZAGEM NA EXTENSÃO UNIVERSITÁRIA}

As duas seções anteriores apresentaram que a concepção da extensão no Brasil ocorreu de forma diferenciada e recentemente foi reconhecida como uma atividade acadêmica, indissociável do ensino e da pesquisa. A universidade teve o ensino como sua primeira função, passando, posteriormente, para a pesquisa, mas somente nos últimos 30 anos foi que teve como reconhecida a sua função de extensão.

Em uma perspectiva contemporânea, essas atividades devem ser equivalentes e merecer igualdade de tratamento. Todavia, na prática, ainda não é isso que ocorre, especialmente no que diz respeito a conceitos. Há um consenso sobre o que significa Ensino e Pesquisa, mas o conceito de Extensão é permeado de muitos equívocos, ambiguidades e incertezas. (GIORA, 2010, p. 216).

Compreende-se que houve um grande esforço do Brasil, nas duas últimas décadas do século XX, para dar significado à extensão universitária, porém a ausência de um texto legal fez com que a abordagem teórica permeasse por diferentes conceitos.

A partir da história da extensão nas universidades brasileiras, percebe-se que essas instituições buscam reconhecimento, principalmente no que se refere à concretização da extensão como compromisso com a comunidade externa à IES, e à contribuição, no processo de aprendizagem, dos envolvidos nesse processo.

Sob essa perspectiva, a extensão seria a expressão do compromisso social do próprio conceito de universidade, da sua função maior, que é 
fazer a diferença no meio onde ela está inserida, contribuindo, assim, para a construção de uma cidadania plena. A universidade, em uma perspectiva ampla, seja pública ou privada, é uma organização humana de natureza comunitária. Ela tem a função e o dever de estar comprometida com a construção da sociedade onde está inserida. "A extensão universitária, caracterizada pela sua potencialidade educacional e social, é um elemento essencial da identidade institucional." (SÍVERES, 2012, p. 15).

Para Saviani (1985, p. 48), “[...] cabe à universidade socializar seus conhecimentos, difundindo-os à comunidade e se convertendo, assim, em uma força viva capaz de elevar o nível cultural geral da sociedade”. Esse conceito de extensão afirma que é necessário aceitar aquilo que a Universidade produz em termos de conhecimento, bem como aquilo que se difunde por meio do ensino, o qual não deve ficar restrito apenas à comunidade interna da IES.

A visão de extensão como "extramuros", de estender à sociedade os conhecimentos produzidos, pode ser interpretada de diferentes formas. A primeira diz respeito à realização da função por meio de ações isoladas, as quais podem ser cursos, assessorias, eventos, conferências ou palestras, que por muitos anos estiveram registrados nos textos legais como sendo função da extensão das universidades. ${ }^{7}$ A segunda pode ser vista como a universidade que contribui para a solução dos problemas da sociedade, atendendo à comunidade e realizando, assim, a integração da IES com ela. A primeira visão, embora trate de "prolongar" conhecimentos à comunidade, não necessariamente necessita de vinculação com o ensino e com a pesquisa, e a ação geralmente ocorre de forma isolada. A segunda embute na extensão a característica de assistência aos mais carenciados da sociedade. Essas interpretações refletem as diferentes visões de extensão que a história deixou como herança.

Sobre a concepção da extensão universitária, em um viés assistencialista, Calderón (2003, p. 37) esclarece:

${ }^{7}$ Textos legais publicados desde 1931, abordados na primeira seção deste capítulo. 
A ideia que está por detrás desse entendimento é basicamente a seguinte: aqueles que têm estendem àqueles que não têm. Essa visão assistencialista traz, pois, uma direção unilateral, ou seja, é uma espécie de rua de mão única: só vai da universidade para a sociedade. A mão inversa não é considerada.

Giora (2010, p. 216) complementa e observa que essa visão de extensão não pode mais ser a única, pois está ultrapassada:

Existem várias concepções de Extensão. A mais tradicional, e já superada, compreende-a como uma prática de atendimento às carências da sociedade, revestida de um caráter assistencialista. Nesse caso, está dissociada do Ensino e da Pesquisa e se constitui em atividades pontuais.

Esses conflitos conceituais permeiam textos publicados a respeito da temática extensão. Autores que se envolvem ou escrevem sobre a extensão enfatizam ser essa a função mais nova da universidade e que, portanto, ainda não possui uma identidade bem definida, o que justificaria, de certo modo, as práticas que confundem responsabilidade social e compromisso social. A universidade, na sua gênese, tem a característica do compromisso com a sociedade onde está inserida, que se difere da responsabilidade social.

Nesse direcionamento, Demo (2005, p. 153-155. Acréscimo meu) afirma que "[...] o compromisso será o lugar da política social do conhecimento [...]. [A universidade] precisa saber colocar o compromisso social dentro de mandatos essenciais, que são: reconstruir conhecimentos e educar novas gerações”.

A concepção de que a extensão deve ser vista como uma atividade geradora de conhecimento ficou registrada, em 1987, no primeiro 
Encontro Nacional de Pró-Reitores de Extensão. As discussões e a prática de extensão passaram a ser coordenadas pelo conceito de mão dupla.

A Extensão é uma via de mão dupla, com trânsito assegurado à comunidade acadêmica, que encontrará, na sociedade, a oportunidade de elaboração da práxis de um conhecimento acadêmico. No retorno à universidade, docentes e discentes trarão um aprendizado que, submetido à reflexão teórica, será acrescido àquele conhecimento. [...] Além de instrumentalizadora deste processo dialético de teoria/prática, a Extensão é um trabalho interdisciplinar que favorece a visão integrada do social. (FORPROEX, 1987, p. 11. Grifos meus).

Essa perspectiva pode estar ancorada na proposta de Síveres (2008), o qual afirma que as relações entre conhecimento, educação e aprendizagem são as especificidades da educação superior. $\mathrm{O}$ conhecimento está vinculado a um percurso educativo e a um processo de aprendizagem.

Ao tratar a extensão como um processo de aprendizagem, é preciso pensar as ações extensionistas em uma dimensão em que os discentes sejam mais ativos, com impacto na sua formação. Tal proposta é confirmada por Freire, ao comentar que a educação é diálogo e não simples transferência de saberes.

O conhecimento não se estende do que se julga sabedor até aqueles que se julga não saberem; o conhecimento se constitui nas relações homem-mundo, relações de transformação, e se aperfeiçoa na problematização crítica destas relações. (FREIRE, 2006, p. 36). 
As ideias e práticas de Freire passam, portanto, a servir como fundamentação de conceitos e práticas extensionistas institucionalizadas desde a década de 80 . Sem desvalorizar as práticas de extensão existentes na história da universidade brasileira, a extensão também começa a ser vista como uma possibilidade para a produção do conhecimento do acadêmico universitário. Para Síveres (2008), trata-se de qualificar a extensão como um percurso aprendente e, assim, buscar um novo direcionamento à ação e à reflexão extensionistas.

Ao partir desse consenso, é importante considerar os sujeitos envolvidos na construção desse conhecimento. Segundo Almeida e Sampaio (2010), os três sujeitos mais significativos nessas vivências são os professores, os estudantes e as pessoas da comunidade. Rabel (2012) compartilha essa ideia ao afirmar que, para caracterizar a extensão, é imprescindível a articulação de três sujeitos: professores, acadêmicos e comunidade.

A definição dos sujeitos e o papel de cada um são fundamentais no conceito de extensão universitária a fim de que ele não recaia em modelos de dois agentes, como, por exemplo, a extensão com o professor atuando na comunidade ou com o professor atuando com o aluno, mas sem a comunidade; ou o aluno atuando na comunidade, mas sem a interlocução do professor.

A comunidade, além de parceira na construção da extensão, que traz as necessidades e demandas para a interação com o acadêmico, também participa do ciclo de aprender e de ensinar, tendo voz ativa e contribuindo para a construção do conhecimento. O aluno, por sua vez, é o ator, o qual tem a função de desenvolver as ações extensionistas, cuja consequência e objetivo são os impactos da sua formação.

O professor é o provocador e mediador, o qual se responsabiliza pela orientação dos acadêmicos. Ele exercita o papel fundamental de levantar os questionamentos e de conduzir o aluno à reflexão e à ação extensionista a fim de que se estabeleça a aprendizagem. 
Nesse sentido, a comunicação entre universidade e comunidade não está mais fundamentada na visão unilateral, na qual a comunidade é a única beneficiada, mas na comunicação entre os sujeitos da ação, ou seja, na troca dos saberes acadêmico e popular, que ocorre por meio da relação dialógica entre universidade e comunidade.

A extensão, além de trazer benefícios para a comunidade, de fazer diferença para a sociedade onde a IES está inserida, deve possibilitar a aprendizagem para o estudante da graduação, pois a escola, mais do que um lugar de ensino, deve ser lugar de aprendizagem, que é visto como uma formação integral do ser humano, dada pelas experiências educativas que ocorrem além dos limites das salas de aula.

Cabe destacar que essa interação entre universidade e comunidade possibilita ao acadêmico o desenvolvimento de competências para além das técnicas e profissionais. Possibilitar a participação do acadêmico em atividades de extensão tem permitido ao discente, além de colocar em prática os conhecimentos da graduação, vivenciar experiências de outra natureza, que contribuem para a formação do ser humano como pessoa mais experiente e preparado para a vida.

O desenvolvimento de atividades em projetos que tenham inserção em comunidade supõe desafios que se apresentam no cotidiano. Dessa forma, o estudante extensionista é desafiado a buscar soluções para as questões presentes que lhe são lançadas em suas tarefas diárias. [...] O aprendizado na extensão universitária não se limita a técnicas de determinada área profissional, mas propicia outros conhecimentos diferenciados que contribuem tanto para o desenvolvimento pessoal como profissional dos estudantes extensionistas. (ALMEIDA, 2012, p. 69-70). 
O papel do professor é perguntar, mediar e conduzir o trabalho. Fazer a Extensão Universitária como um processo descentralizado do docente incentiva a autonomia dos acadêmicos e contribui para a sua formação pessoal. Assim, acredita-se que a extensão contribui com valores, posturas e condutas comportamentais. A conquista pessoal reflete que a extensão deve contribuir para a finalidade educacional da instituição, que é formar uma pessoa para além da sua área de atuação técnica, ou seja, formar um cidadão para enfrentar as dificuldades postuladas pela vida. É assim que deve ser visto o processo de aprendizagem, baseado nas observações próprias do acadêmico e em atitudes reflexivas que provêm do diálogo e da interação com a realidade, promovendo a conscientização crítica e ensinando a lidar com o próximo, com as pessoas e com o mundo.

Zabala (2010) enfatiza que as finalidades da educação devem ser dirigidas ao desenvolvimento de todas as competências necessárias para responder aos problemas que a vida apresenta. Essas competências vão além do âmbito profissional. A extensão também permite o desenvolvimento de competências de âmbito social, interpessoal e pessoal. No âmbito social, significa participar ativamente na transformação da sociedade, enquanto na dimensão interpessoal é educar para compreender melhor os demais, além de saber se comunicar, aprender a dialogar e ser solidário com os indivíduos. Por fim, o âmbito pessoal significa formar cidadãos mais autônomos, com responsabilidade crítica e capazes de compreender o mundo e a si mesmos.

Enfim, a extensão, além de contribuir para a formação técnico-científica do acadêmico e cumprir a finalidade da instituição de ensino de estender o conhecimento nela produzido para a comunidade, tem a função de postular uma aprendizagem significativa no âmbito humanístico, envolvendo o desenvolvimento das competências pessoais, interpessoais e de transformação da sociedade. 


\section{CONSIDERAÇÕES FINAIS}

A universidade é uma instituição responsável pela formação do ser humano. Há um consenso de que a universidade tem como responsabilidade exercitar três atividades fundamentais, que são requeridas para a excelência do ensino superior: o ensino, a pesquisa e a extensão. $O$ processo histórico da universidade brasileira mostra que a extensão ocorreu por meio de diferentes práticas e, consequentemente, acarretou em diferentes modelos de extensão. Dentre eles, é unânime enxergar a extensão como um dos meios pelos quais a IES exerce seu compromisso social. A extensão é vista como uma ponte entre a universidade e a comunidade. A história e os textos referentes à temática mostram que a extensão, além de contribuir para a função social da universidade, era vista com sentido apenas unilateral, como uma forma de a universidade "estender" os conhecimentos produzidos nos meios acadêmicos para a comunidade ao seu redor.

Mais tarde, a partir da década de 80, com a criação dos Fóruns de Extensão das IES, ela começou a aparecer nos documentos oficiais do governo, assumindo uma conotação mais acadêmica e refletindo sobre a contribuição da extensão e o impacto na formação do estudante. Com isso, definem-se os três sujeitos do fazer Extensão Universitária e o papel de cada um. $\mathrm{O}$ fazer da extensão decorre da articulação entre estudante, professor e comunidade. Conclui-se que o estudante deve ter um papel ativo na extensão, ou seja, é ele quem desenvolve as ações e, portanto, ao lado da comunidade, constrói e ressignifica o conhecimento técnico e científico por meio da relação dialógica que exerce com a comunidade, mediada pelo professor. A extensão tensiona a hegemonia da educação formal e exige dos sujeitos horizontalizar as relações entre universidade e comunidade, a fim de estabelecer uma nova relação com o saber. A produção do conhecimento ocorre em uma perspectiva em que os diferentes saberes estão imbricados. 
Aliado ao novo Plano Nacional de Educação (2014-2024), que apresenta como meta para as Instituições a inserção de $10 \%$ dos créditos curriculares em programas e projetos de extensão, novos conceitos de sala de aula e/ou de flexibilização surgiram como forma de fazer com que a extensão seja inserida nos currículos, possibilitando ao estudante escolher os projetos dos quais pretende participar, bem como construindo as particularidades do seu próprio currículo. A promoção de espaços de aprendizagem diversificados contribui diretamente para a motivação do aprender dos estudantes. Essas experiências universitárias são importantes marcos na vida acadêmica.

Enfim, as atividades de extensão são vistas como um espaço de aprendizagem que contribui para o processo aprendente que, por sua vez, é fortalecido no momento em que o aluno deve enfrentar as diferentes situações impostas pela realidade. A extensão é vista como um espaço privilegiado para a formação da pessoa. Acredita-se que a extensão contribui para a função maior da universidade, que é a aprendizagem para o estudante, no sentido de prepará-lo para a vida, ou seja, não somente preparar para uma área de atuação, mas para enfrentar novos desafios e torná-lo um cidadão competente.

\section{REFERÊNCIAS}

ALMEIDA, L. P. A extensão universitária: processo de aprendizagem do aluno na construção do fazer profissional. In: SÍVERES, L. (Org.). Processos de aprendizagem na extensão universitária. Goiânia: PUC, 2012.

ALMEIDA, L. P.; SAMPAIO, J. H. Extensão universitária: aprendizagens para transformações necessárias no mundo da vida. Revista Diálogos: Construção Conceitual de Extensão e outras reflexões significativas. Brasília, v. 14, p. 33-41, 2010. 
BRASIL. Decreto n ${ }^{\circ} 19.851$, de 11 de abril de 1931. Dispõe que o ensino superior no Brasil obedecerá, de preferencia, ao systema universitario, podendo ainda ser ministrado em institutos isolados, e que a organização technica e administrativa das universidades é instituida no presente Decreto, regendo-se os institutos isolados pelos respectivos regulamentos, observados os dispositivos do seguinte Estatuto das Universidades Brasileiras. Diário Oficial [da] República Federativa do Brasil. Brasília, DF, 15 de abril de 1931, p. 5800. [Publicação Original] Disponível em: <http://www2.camara.leg.br/legin/fed/decret/1930-1939/decreto-1985111-abril-1931-505837-publicacaooriginal-1-pe.html>. Acesso em: 10 ago. 2014.

BRASIL. Lei no 4.024, de 20 de dezembro de 1961. Fixa as Diretrizes e Bases da Educação Nacional. Diário Oficial [da] República Federativa do Brasil. Brasília, DF, 27 de dezembro de 1961. Seção 1. Disponível em: <http://www2.camara.leg.br/legin/fed/lei/1960-1969/lei-4024-20-dezembro-1961-353722-publicacaooriginal-1-pl.html>. Acesso em: 10 ago. 2014. BRASIL. Lei no 4.881, de 6 de dezembro de 1965. Dispõe sôbre o Estatuto do Magistério Superior. Diário Oficial [da] República Federativa do Brasil. Brasília, DF, 10 de dezembro de 1965. Disponível em: <http://www. planalto.gov.br/ccivil_03/LEIS/1950-1969/L4881A.htm>. Acesso em: 10 ago. 2014.

BRASIL. Lei no 5.539, de 27 de novembro de 1968. Modifica dispositivos da Lei número 4.881-A, de 6 de dezembro de 1965, que dispõe sôbre o Estatuto do Magistério Superior, e dá outras providências. Diário Oficial [da] República Federativa do Brasil. Brasília, DF, 29 de novembro de 1968, retificada aos 3 de dezembro de 1968a. Disponível em: <http://www. planalto.gov.br/ccivil_03/LEIS/1950-1969/L4881A.htm>. Acesso em: 10 ago. 2014.

BRASIL. Lei no 5.540, de 28 de novembro de 1968. Fixa normas de organização e funcionamento do ensino superior e sua articulação com a escola média, e dá outras providências. Diário Oficial [da] República Federativa 
do Brasil. Brasília, DF, 23 de novembro de 1968, retificada em 3 de dezembro de 1968b. Disponível em: <http://www.planalto.gov.br/ccivil_03/LEIS/ L5540.htm>. Acesso em: 10 ago. 2014.

BRASIL. Constituição da República Federativa do Brasil (1988). Diário Oficial [da] República Federativa do Brasil. Brasília, DF, 5 de outubro de 1988. Disponível em: <http://www.planalto.gov.br/ccivil_03/constituicao/ constituicao.htm>. Acesso em: 10 jun. 2014.

BRASIL. Lei n 9.394, de 20 de dezembro de 1996. Estabelece as diretrizes e bases da educação nacional. Diário Oficial [da] República Federativa do Brasil. Brasília, DF, 23 de dezembro de 1996. Disponível em: <http://www. planalto.gov.br/ccivil_03/leis/19394.htm>. Acesso em: 23 nov. 2013.

BRASIL. Decreto-lei n ${ }^{\circ}$ 10.172, de 09 de janeiro de 2001. Aprova o Plano Nacional de Educação e dá outras providências. Diário Oficial [da] República Federativa do Brasil. Brasília, DF, 10 de janeiro de 2001. [Edição Extra] Disponível em: <http://www.planalto.gov.br/ccivil_03/leis/ leis_2001/110172.htm>. Acesso em: 10 ago. 2014.

BRASIL. Decreto-lei ${ }^{\circ} 10.861$, de 14 de abril de 2004. Aprova o Sistema Nacional de Avaliação da Educação Superior - SINAES e dá outras providências. Diário Oficial [da] República Federativa do Brasil. Brasília, DF, 15 de abril de 2004. Disponível em: <http://www.planalto.gov.br/ccivil_03/_ato2004-2006/2004/lei/110.861.htm>. Acesso em: 10 ago. 2014.

BRASIL. Decreto-lei n ${ }^{\circ}$ 13.005, de 25 de junho de 2014. Aprova o Plano Nacional de Educação e dá outras providências. Diário Oficial [da] República Federativa do Brasil. Brasília, DF, 26 de junho de 2014. Disponível em: <http://www.planalto.gov.br/CCIVIL_03/_Ato20112014/2014/Lei/L13005.htm>. Acesso em: 10 ago. 2014.

CALDERÓN, A. I. Extensão universitária: institucionalização sem exclusão. Revista Educação Superior, Piracicaba, v. 53, p. 36-38, 2003. 
DEMO, P. Educar pela pesquisa. 7. ed. Campinas: Autores Associados, 2005.

DUCH, F. F. Interface extensão universitária e cultura interdisciplinar. 2006. 97 f. Dissertação (Mestrado em Semiótica Tecnologias da Informação e Educação) - Universidade Braz Cubas, Mogi das Cruzes, 2006.

FÓRUM DE PRÓ-REITORES DE EXTENSÃO DAS UNIVERSIDADES PÚBLICAS BRASILEIRAS - FORPROEX. Conceito de extensão, institucionalização e financiamento. Porto Alegre: UFRGS, 1987. Disponível em: <http://www.renex.org.br/documentos/Encontro-Nacional/1987-IEncontro-Nacional-do-FORPROEX.pdf>. Acesso em: 23 nov. 2013.

- Indissociabilidade ensino-pesquisa-extensão e a flexibilização curricular: uma visão da extensão. Porto Alegre: UFRGS, 2006. Disponível em: <http://www.renex.org.br/documentos/ColecaoExtensao-Universitaria/04-Indissociabilidade-Ensino-Pesquisa-Extensao/ Indissociabilidade-e-Flexibilizacao.pdf>. Acesso em: 09 jun. 2015.

Extensão universitária: organização e sistematização. Belo Horizonte: Coopmed, 2007. Disponível em: <http: http://www.renex. org.br/documentos/Colecao-Extensao-Universitaria/06-Organizacao-eSistematizacao/Organizacao-e-Sistematizacao.pdf>. Acesso em: 09 jun. 2015.

. Plano Nacional de Extensão Universitária. Ilhéus: Editus, 2001, p. 29.

FRANCO, L. R. H. R.; SILVEIRA, M. S.; BRAGA, D. A EaD transformando as técnicas de aprendizagem da engenharia. In: WORLD CONGRESS ON ENGINEERING AND TECHNOLOGY EDUCATION, 2004, Guarujá. Anais... Santos, SP: UNISANTOS, 2004. Disponível em: <http://www.ead. unifei.edu.br/biblioteca/LivroDigital/iee/extensao/capacitacaoM2/tecnicas_ensino.html>. Acesso em: 14 set. 2015. 
FREIRE, P. Pedagogia da Autonomia: saberes necessários à pratica educativa. 33. ed. São Paulo: Paz e Terra, 2006.

GIORA, R. C. F. A. Extensão universitária: um caminho possível para otimizar a prática extensionista numa universidade comunitária confessional. In: STALLIVIERI, L. (Org.). Gestão e liderança universitária. Florianópolis: Tribo da Ilha, 2010.

NOGUEIRA, M. D. P. Extensão universitária no Brasil: uma revisão conceitual. In. FARIA, D. S. (Org.). Construção conceitual da extensão na America Latina. Brasília: UNB, 2001.

RABEL, L. C. Os sujeitos envolvidos no fazer da extensão Universitária. In: SÍVERES, L. (Org.). Processos de aprendizagem na extensão universitária. Goiânia: PUC, 2012.

SAVIANI, D. Ensino público e algumas falas sobre universidade. São Paulo: Cortez, 1985.

SÍVERES, L. A extensão como um princípio de aprendizagem. Revista Diálogos: Universidade do Século XXI. Brasília, v. 10, p. 8-17, 2008.

- Perspectivas de aprendizagem na extensão universitária. In: SÍVERES, L. (Org.). Processos de aprendizagem na extensão universitária. Goiânia: PUC, 2012.

SÍVERES, L. et al. Diretrizes de extensão. Brasília: Universa, 2009. Disponível em: <http://www.ucb.br/sites/000/2/DiretrizesDeExtensao. pdf $>$. Acesso em: 10 jun. 2014.

SOUSA, A. L. L. A história da extensão universitária. Campinas: Editora Alínea, 2000.

ZABALA, A. Como aprender e ensinar competências. Porto Alegre: Artmed, 2010. 